\title{
How important is mentoring in education?
}

\author{
Carmen Sonia Duse ${ }^{1, *}$, Dan Maniu Duse ${ }^{2}$, and Maria Karkowska ${ }^{3}$ \\ ${ }^{1}$ Lucian Blaga University of Sibiu, Department for Teacher Training, 34 Calea Dumbravii, Sibiu, \\ Romania \\ ${ }^{2}$ Lucian Blaga University of Sibiu, Department of Industrial Machines and Equipment, 4 Emil \\ Cioran, Sibiu, Romania \\ ${ }^{3}$ Krakowskie Centrum Zarzadzania i Administracji Sp. z o.o. 31-157 Krakow, Plac Matejki 10/3, \\ Poland
}

\begin{abstract}
The paper aims to provide the mentoring experience made in Romanian schools, developed as a result of the Erasmus + project entitled "Mentoring Between teachers from secondary and high schools" project No. 2014-1-PL01-KA200-003335. Thus, we seek to present the work and the general considerations in connection with the mentoring theme, how we decided on the curriculum in order to form mentors, how mentors were selected and what was the result of their mentoring work. It is important to observe the main obstacles in the mentoring process were and how these problems could be solved. We will also highlight the impact of the mentoring activity on mentees and their perceptions about the usefulness of such activities. The project design and the activities undertaken are the results of research and brainstorming made by teams of specialists who participated in the project and are conceived by university professors and researchers from Poland (project coordinator), Portugal, Spain, Greece and Turkey and also Romania. The teachers involved in the project were from the secondary and high schools from the Counties of Sibiu, Brasov, ClujNapoca and Iasi. We thought the geographical dispersion will be very useful to establish comparative elements between the involved schools.
\end{abstract}

\section{About Mentoring}

Formally, mentoring as a problem in Romania would be described nowadays as a new one. Informally, there have always been people who programmatically or not, behaved as mentors.

But we have to ask ourselves: what is a mentor and who can play this role? Mentor can be considered "a trusted counsellor" or "a guide".

The term's origin is attributed to Homer, and binds to ancient Greek mythology, when talking about the character reminded, the Greek epic Trojan War, Odysseus Mentor was a friend to whom he entrusted his son Telemachus for support and guidance. Athena, the goddess of wisdom, got sometimes into the role of a Mentor and offered encouragement and support to Telemachus, for learning and enlightenment. From this story, the word "mentor" is derived and has come to mean a "father" or even a "mother figure" (according

${ }^{*}$ Corresponding author: carmen.duse@,ulbsibiu.ro 
to the wisdom and advice of Athens) for youngsters. Later, being associated with the terms of a teacher or a counsellor, the term "mentor" will be seen and used in the schools of Socrates and Plato, and in Aristotle's academy.

In other social and literary contexts the term "mentor" can be seen as "advisor", "instructor", "teacher", "guru", "Sensei”, "coach". In some specific situation, the word mentor can be used for anyone who has a positive or a guiding influence on another person in his life.

The definitions of the term "mentor" are manifold. Thus, as recorded by Wai-Packard "Mentoring is a term generally used to describe a relationship between a less experienced individual, called a mentee or protégé, and a more experienced individual known as a mentor" [1].

In [2] it is stated that "mentoring is most often defined as a professional relationship in which an experienced person (the mentor) assists another (the mentee) in developing specific skills and knowledge that will enhance the less-experienced person's professional and personal growth."

An interesting part is that the parent of the management - Frederick Taylor (1911) stated in "Principles of Scientific Management" that: "what we all want is a competent person, already prepared; someone, who has been trained by someone else. But we will not find ourselves on the path to national efficiency as long as we will not realize that it is not only our duty, but also our chance consists in the systematic collaboration for education and training of this competent person, instead of seeking a man who already prepared others."

Mentoring the next generation of teachers is a huge responsibility project for current teachers and school managers. The need to maintain mentoring in secondary and high schools, but not only, is pressing at the moment, mainly because of the lack of attractiveness of the job so that young people tend to abandon the teachers profession mainly because of economic reasons. As John Holloway [3], director of the Educational Testing Service's Teacher Quality Initiative stated "One of the greatest reasons new teachers leave the profession is lack of support and assistance in dealing with the many frustrations they face. Mentoring plays a nurturing role in guiding those new teachers through the first critical years and in providing them with tools and skills needed in actual practice."

Therefore the Erasmus + Project entitled "MENTOR - Between Mentoring teachers in secondary and high schools" No. 2014-1-PL01-KA200-003335 has come to meet this need $[4]$.

\section{The MENTOR Project}

The Mentor project included six partners from six different countries (Poland, Romania, Portugal, Spain, Greece and Turkey), being coordinated by the Krakowskie Centrum Zarzadzania i Administracji Sp. z o.o. and was conducted over a period of 3 years (20142017). The MENTOR project's focus was to support the growth and professional development of new teachers in secondary and high schools by means of mentoring. The proposed specific objectives of the MENTOR project were:

1. To organize the desk research about the methods (models) of mentoring, especially between teachers in secondary and high schools in EU countries.

2. To elaborate the method (model) of mentoring between teachers in secondary and high schools.

3. To design and develop the training modules for secondary and high school teachers mentors.

4. To organize a set of Training for Teachers Mentors (TTM) aimed in familiarizing teachers in the mentoring skills using an on-line/blended approach. 
5. To establish a joint infrastructure in order to facilitate sustainable accessibility to the mentoring approach for schools as well as the exchange of scientific information.

6. To test delivered mentoring method in the secondary and high schools.

7. To monitor the dissemination, impact measurements and the quality assessment of the project.

\subsection{Desk research about the methods (models) of mentoring in EU countries}

The bibliographical research undertaken by the participating teams has gathered a large number of bibliographic materials from which later started the conceiving of the training method (model) [5-7].

We opened the desk research using key - words like: mentor, mentoring process, beginner teacher, mentees, new entrants. It was useful, for the beginning to understand more about who can be a mentor, what qualities are needed, if he needs previous experience as mentor and what kind of experience, some about the ethic of mentoring process and other more.

More than 50 resources, blogs, sites regarding the Mentor and Mentoring process was analysed in order to understand the way of thinking of these specialists in this field and about 38 of them were chosen as a model and for a deeper analyse. In the first step, the research was focused on the mentoring process in general, and in the second step on the educational field. It was interesting for us to understand how the problem of beginner teacher was solved in other countries or continents, as we collect information from all around the world.

In this first step we found differences between the European countries from the mentoring point of view. As an example, there were countries in which there is no idea about the mentoring process, as well as there are European countries which have a specific legislation for that. All these situations were examined and judged in order to find the best way of mentoring proposal.

\subsection{The development of the training method}

Bibliographical research helps us have a clear image over the best option in training the junior teachers. In order to achieve the training curriculum several lots of teachers from partner countries were investigated over the usefulness and importance of certain skills and essential detailed knowledge of beginning teachers. Initially we proposed that this part of formal curriculum to be one small stretch, not to overburden the novice teachers.

To test the importance of training curriculum, each participant has worked with a number of minim 20 mentors. These over 100 mentors have been trained in a special session, conducted during one day, in which the produced materials were presented and the teachers were asked about their opinion on the appropriateness/suitability of these materials in order to work with beginning teachers.

The offered feed-back by these mentors of the 6 participating countries was extremely useful to complete the first theoretical part. Thus, besides the short version of the handbook's work a supplement to the handbook has been done as well. The logic of its occurrence related discussions resulted in the initial phase of the mentors training, where the idea of existence of more materials dedicated to the individual study for either the mentors and teachers juniors, or even other teachers was present.

Secondly, after the feed-back received from the mentor training, a training kit has been created, a collection of worksheets, PowerPoint presentations and case studies for the training of the junior teachers. 
Once these instruments were operationalized, the testing phase of these instruments went on directly in schools.

Thus, the process of training of junior teachers began in every participating country using the tools designed for the first two years of the project.

\section{The Training of beginners}

\subsection{Teachers through Mentoring}

The training step for novice teachers was conducted over a period of nine months, during which the novice teachers and the mentors met weekly at first, then once every two weeks. Practical training was conducted between September 2016 and the end of May, 2017. Questionnaires to the mentors and to the mentored were applied at the end of the first half and at the end of the training stage in order to collect the feed-back of that activity.

For starters, in August 2016, the most difficult problem that had to be urgently solved was the establishment of the included schools in the testing phase, because the number of the junior teachers in Romanian schools was found to be becoming smaller. But the even bigger surprise was when they found the same situation in other participating countries. This can be blamed either on the negative demography, but also on lack of attractiveness of the teaching profession for young graduates. As a result, for Romania, the test group included six mentors and six mentees form four schools. There were involved one secondary school and three vocational high schools, one of them from a rural area.

The project directors from the involved schools and high schools have expressed their agreement by signing a cooperation protocol. They also assured their mentoring support for the first 4 months.

Out of the six mentors, five of them were women and only one was male. Their age was between 30 and 50 and four of them were aged between 30 and 40 years $(66.6 \%)$, while the other two were between 40 and 50 years old (33.3\%). Among the surveyed mentors, only one had previous experience of mentoring.

The reason they accepted the mentoring activity was because they considered this activity as a challenging and interesting one.

Also, the middle age of the involved teachers as a mentor is one that demands new challenges. Most of them are teachers who have achieved professional degrees, academic degrees (grade II and I, which in the Romanian educational system scale is the maximum for professional development in pre-university schools) and now they are looking for new ways of self-realization.

The mentees group comprises 6 people, 5 women and one man. Their age is as follows: - one person (female) under 25 years $(16.6 \%)$;

- three persons between $25-30$ years $(50 \%)$;

- two persons between $31-35$ years $(33.3 \%)$.

None of the mentors had previous experiences of mentoring. The reasons they accepted mentoring activity was because:

- It appeared as an exciting and challenging activity;

- They were convinced by mentors involved in the program;

- They felt the need for personal development.

The meetings between the mentors and the mentees were held mostly face-to-face, for a period of more than an hour, but also by communicating through e-mail or chat. B means of the face-to-face meetings both mentors and mentees were easier to clarify certain aspects of mentoring. 
What made it more remarkable was that the meetings were held in their free time, usually in the school. Opinions have shown that the most difficult problem was to find their free time.

Even if a lot of the factors were considered very important in the mentoring relationship, the first place was taken by mutual understanding, acceptance and regular feedback from both sides. This may betray the mentees uncertainty and their need to receive confirmation that they are on the right way.

As shown above, questionnaires to observe the conduct and effectiveness of the mentoring program were applied. Thus, both mentors and mentees were questioned as on the question "what were the most important / valuable benefits mentors and mentees individually received so far from this cooperation?"

The mentors came up with the following answers:

- The mentees involvement.

- The decision of a mentee to consult the mentor even outside the scheduled meetings.

- One mentee hugged the mentor one day and thanked him for everything they have shared together, saying that their relationship there is still work and practice to do for the methods and teaching techniques.

- They consider everything could be solved through trust.

- They learned to manage the personal resources.

- The self-confidence, the mentee earned, which was visible in the accurately drawing of documents for the school and the grade she received in the completed inspection.

- They learned to be more confident.

- They learned to discover their own resources needed for conducting an effective teaching process.

From the mentors' perspective, one mentor said: "This cooperation really helped me to evaluate myself both as a teacher and a friend / colleague, open to share experiences and examples of good practice to stimulate a person willing to apply their knowledge in a personal activity. I found, that it's wonderful to give, to stay close to others with love and to communicate with the other, who is interested in the knowledge." Another mentor considered "I'm available, more than I thought".

The answers of others conclude, that: was a real help for his work in the classroom; the mentoring trust that she seems to receive, as she advances both in her emotionally and professionally life.

For the mentees, most important / valuable benefits were:

-The job as a teacher is made with much, much more love and many sacrifices for the teacher.

- They learned to work more effectively with students.

- The professional behaviour, which is required for a teacher.

- The richness of the information which they were provided with.

- Application related design of the lesson plans, achieving the initial tests.

- Facilitating best practice by sharing experience.

Mentors and mentees were asked "what they have learned about themselves, their abilities, knowledge and attitudes so far from this cooperation?" as well. There are different answers, from mentors and mentees. For example, the mentees stated, that:

- They consider it to be very important to know how to control emotions, not to panic, to be patient and always act calmly.

- They understand they can give more than they thought.

- There is always something new to learn.

- Through the careers it can be possible to improve methodical knowledge and skills. This is visible when someone is trying to share their knowledge with other teachers. 
- It is good sometimes to see again the teaching profession from the perspective of a newcomer in education.

The last question was related to the additional comments from mentors and mentees (thoughts, feelings, suggestions) about the Testing Phase progress. You can see here examples such as:

"The mentoring activity held during this period encouraged me to keep being available to those who needed support to start their teaching career. The mentee opening her desire to do everything better and more efficiently, foster cooperation and to share joy, to determine experiences, knowledge, materials and much love. Through our work with mentee, we noticed visible progress in the quality of her educational activity."

Other opinions mentors gave, were:

- There were moments of fatigue, but they overcame them.

- With mentoring activity there were only positive feelings connected.

- Mentoring is an exercise for success. This program implemented in schools would only bring benefits for novice teacher, as well as for the school. Through this program the relationships between colleagues could improve a lot.

- It's an enjoyable and exciting experience.

The 6th mentor had a reflection moment: "In this test phase I realized that mentoring is extremely important because it makes you see with new eyes things already tested and learned and to understand the approach of beginning of a teaching career."

Mentees gave important feed-back as well:

"Activities carried out with mentor in this period were very useful for me. Due to the opportunity I had, I learned many practical and beneficial things for my teaching career. The warmth and love that we received during this period from the mentor and my colleagues made me want to continue this path, which I have chosen in education."

Another mentee said: "It was a very interesting and formative experience and I would have preferred to have this experience during my university time."

Other feed-back from the novice teachers included:

- Mentoring is a very useful experience for any newcomer in school.

- It is a very useful experience for the novice teachers. Everyone should benefit from it.

- The introduction of this program in all Romanian should be mandatory.

\section{Conclusion}

Despite the problems in finding the needed time, which is always too short because of their duties and responsibilities, mentors and mentees found a special time for them and their relationship. For mentors it was a good moment to understand the novice teachers' needs and to remember their first steps in teaching career. For mentees it was encouraging to have a person who can help them in different situation. From the point of view of subject discussions, the focus was in didactics and pedagogical design as well as in organizational culture and classroom management.

A good and encouraging point was for the mentors the desire of progress and development of the mentees.

From the mentees perspective, the most appreciated feature of the mentors was the desire for help and the open relation which was built.

A strong professional development of the mentors facilitates the relationship, but in the same way, it was important for the development of these good relationship concerning mentors human qualities.

And on the first place here is the Emotional Intelligence of the mentors which was proved. 
Looking of the geographical dispersion of the mentors, an important conclusion can be seen. The relationship between mentors and mentees in the Counties of Iasi and in Cluj are warmer, with more positive emotions. In the high-schools and secondary schools from Sibiu and Brasov County, which are in the heart of Romania, the relationships are more formal, more distant. This could be in connection with the specific culture of these parts of the country. The people from Transylvania are seen colder and more distant in relationships then the habitants from the other parts of Romania.

Following the experience of mentoring achieved in the six partner countries, a conclusion can be drawn: Mentoring is a must that has to exist, no matter what we are talking about: young teachers starting their career or teachers in a new school.

Each of us needs some time for integration and learning / suitability in the organizational behaviour and as short as we can make it, by keeping a high standard of quality, the more productive we are as professionals, regardless of the area in which we work and the more in the educational environment.

The specialty literature presents the idea of the unconscious incompetence, when we are not aware of what we are wrong, and persist in these errors, conscious incompetence when we realize that we do something new than we would like, but we do not know how to get it right, conscious competence, that we think we could do a certain thing better, if we focus on it, and unconscious competence when everything becomes normal and we can turn our attention to other things. The presence of the mentor is to ensure the implementation and strengthening awareness, which is the key element in achieving individual progress.

Shaw presents us: "As a form of professional development, mentoring affects both the new teachers who are being mentored, and the experienced teachers, who will serve as mentors" [6]. Through this, we can understand that the winners of the mentoring process would be everyone: mentees, mentors, school members, students and parents, community.

And as the writer Kamand Kajouri once said: "Do not give them a candle to light the way, teach them how to make fire instead. That is the meaning of enlightenment."

\section{References}

1. B. Wai-Packard, Science Mentoring Research, Definition of mentoring, http://ehrweb.aaas.org/sciMentoring/Mentor_Definitions_Packard.pdf (American Association for the Advancement of Science, 2003)

2. D. Cutler, Why New Teachers Need Mentors, https://www.edutopia.org/blog/why-new-teachersneed-mentors-david-cutler (Edutopia, George Lucas Educational Foundation, 2014)

3. Management Mentors, http://www.management-mentors.com/resources/corporate-mentoringprograms-resources-faqs (North America/Europe/Africa, 2015)

4. The Erasmus + Project Mentor - Mentoring between teachers from secondary and high schools, Project No. 2014-1-PL01-KA200-003335, http://edu-mentoring.eu/ (2014)

5. Education World Inc., Guidance from the Get-Go: Mentoring New Teachers, http://www.educationworld.com/a_admin/admin/admin260.shtml (2016)

6. R. Shaw, E. Villegas-Reimers, Teacher professional development: an International review of the literature (UNSECO: International Institute for Educational Planning, 2003)

7. G. Waugh, J. Lovatt, Guide for mentors 2014-2015, http://www.ianphi.org/ (2014) 